\section{Comparison of Conventional and Flouroless Catheter Ablation for Focal Atrial Tachycardia}

\author{
Abstract: \\ Objective: This study sought to evaluate conventional and flouroless catheter ablation for focal \\ atrial tachycardia. \\ Method: 112 patients of atrial tachycardia were divided into 2 groups. Group I consisted of 73 \\ patients who underwent conventional catheter ablation. Group II consisted of 43 patients who \\ underwent the flouroless catheter ablation (39 patients of the first procedure and 4 patients \\ met with failure of the conventional catheter ablation)
}

Results: The first procedure acute successful rate in group II was significantly higher than in group I ( $94.8 \%$ versus $86.3 \%$, respectively; $p<0.05)$. The fluoroscopy time, and radiofrequency delivery time of group I was significantly longer than the group II, respectively $(904.26 \pm 547.56$ seconds in group I versus $169.21 \pm 85.66$ seconds in group Il; $p<0.001) ;(157.32 \pm 81.82$ seconds in group I versus $95.87 \pm 55.24$ seconds in group II; $p<0.001$ ). The number of radiofrequency applications of group I was significantly higher than group II (8.65 \pm 8.15 times versus 6.05 \pm 4.69 times respectively; $p<0.01)$. However, there was no significant difference between 2 groups in procedure time (78.71 \pm 38.76 minutes in group I versus $76.34 \pm 36.48$ minutes in group II; $p=N S)$. After 6 months follow-up, $7.9 \%$ in group I and $5.3 \%$ in group II had a recurrence of atrial tachycardia.

Conclusion: The fluoroless catheter ablation enhanced a more successful rate than the conventional catheter ablation. The fluoroless catheter ablation can reduce fluoroscopy time, radiofrequency delivery time and the number of radiofrequency applications compared to conventional catheter ablation.

Keywords: Atrial Tacycardia-flouroless catheter ablation-conventional catheter ablation

\section{Introduction}

Focal atrial tachycardia (AT) is an uncommon arrhythmia. It accounts for $5 \%-17 \%$ of patients with supraventricular tachycardia [1]. Focal AT arises from a single site within the right or left atrium, in contrast to macroreentrant AT (eg, atrial flutter), which involves multiple sites or larger circuits. Focal AT may occur in the patients (pts) with heart disease such as heart failure, congenital heart disease, ischemic heart disease, pulmonary decompensation, infection, excessive alcohol ingestion, hypokalemia, hypoxia, stimulants, cocaine ingestion, post-heart surgery, post atrial fibrillation catheter ablation and without structural heart disease [24]. Due to the poor efficacy of pharmacologic therapy, catheter ablation may be definitive therapy for these patients. Recently, the non-fluoroscopic mapping system is becoming the more widespread use of the electrophysiology laboratory. However, there is very limited data available comparison of conventional and flouroless catheter ablation for focal atrial
Pham Nhu Hung ${ }^{1 *}$, Trinh Dinh Hoang ${ }^{2}$, Nguyen Van Dan", Nguyen Xuan Tuan', Pham Van Tung ${ }^{1}$

'Hanoi Heart Hospital, Hanoi, Vietnam. ${ }^{2}$ Thanh Hoa General Hospital, Thanh Hoa, Vietnam

*Author for correspondence: E-mail: phamnhuhung@hotmail.com Received date: April 06, 2020 Accepted date: April 20, 2020 Published date: April 27, 2020 
tachycardia. The aim of the present study was to compare between conventional and flouroless catheter ablation for focal atrial tachycardia.

\section{Patients and Methods}

Patients: We collected 112 patients of focal AT of 3643 patients who underwent catheter ablation at Hanoi Heart Hospital from January 2015 to September 2019. 112 patients were divided into 2 groups. Group I consisted of 73 patients who underwent conventional catheter ablation. Group II consisted of 43 patients who underwent the flouroless catheter ablation (39 patients of the first procedure and 4 patients met with failure of the conventional catheter ablation) (Figure 1).

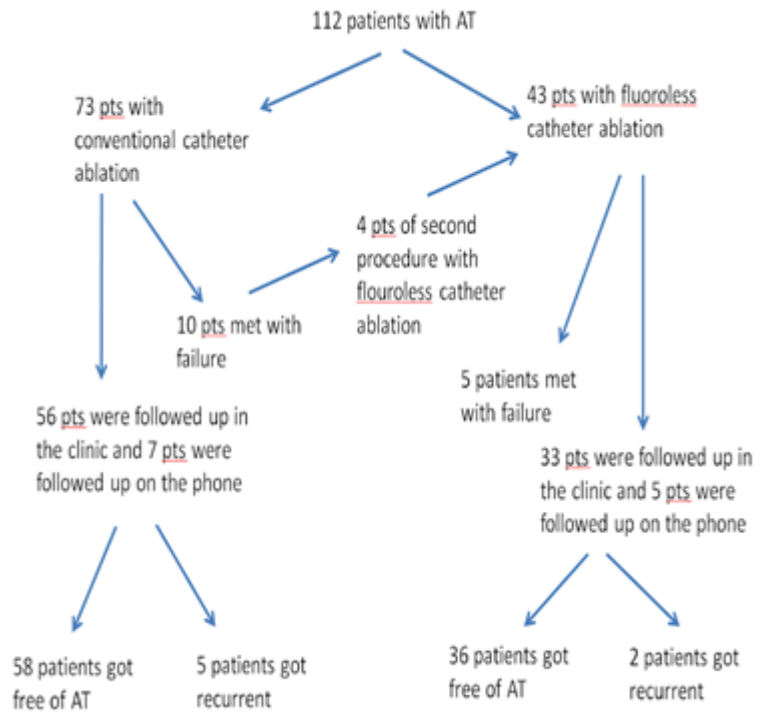

Figure 1: Flow diagram of the study process.

Study methods: the retrospective observational study. Mapping and ablation procedure: In general, three catheters (4-6F) were positioned at the right ventricular apex, His bundle region, and right atrium using the femoral vein approach and the coronary sinus (CS) using the left sub-clavian vein or femoral vein approach. In the electrophysiological study, it was done using standard protocols. The criteria were used to confirm the diagnosis of AT [5]: (1) tachycardia induction and maintenance independent of atrioventricular nodal conduction or presence of anterograde atrioventricular block during tachycardia; (2) inability to advance atrial activation by ventricular premature beats delivered during tachycardia at a time of His bundle refractoriness; and (3) electrogram sequence immediately after ventricular paced beats showing an "atrial-atrial-ventricular" pattern. In the group I, we mostly used a 20 polar catheter (Duo-Decapolar 7F) in the right atrium (Figure 2).

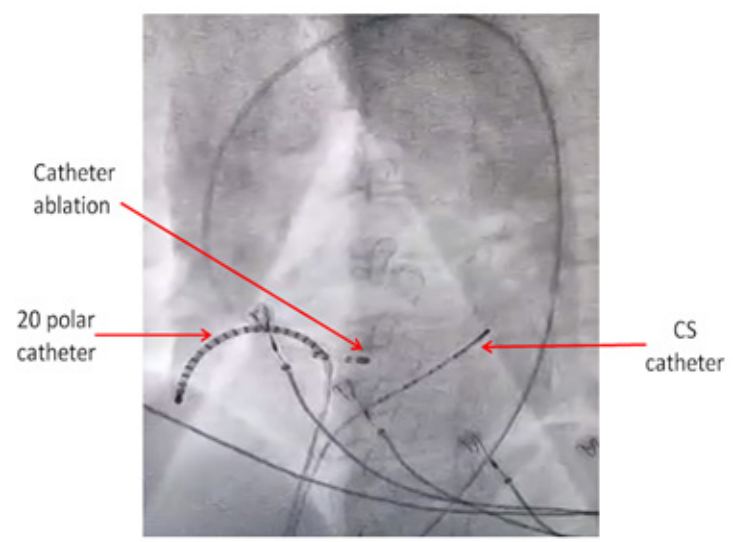

Figure 2: A 71-year-old male patient with AT in the non-coronary cusp, the ablation catheter was performed from the right femoral artery approach. The 20 polar catheter (Duo-Decapolar 7F) was used to map in the right atrium. The successful ablation site located in non-coronary cusp.

In group II, the non-fluoroscopic mapping system used Ensite Velocity (St Jude Medical) during the entire procedure. The atrium was constructed geometry by Inquiry catheter (7F) (Figure 3). An ablation catheter (7F, $4 \mathrm{~mm}$ tip) was typically introduced using the right femoral vein approach if the AT was localized to the right atrium and using a trans-septal approach if the AT was localized to the left atrium. In cases where the AT was localized to the non-coronary cusp, the ablation catheters were using the right femoral artery approach (Figure 2). The radiofrequency (RF) ablation was applied in an activation time of at least 20 ms before the onset of the P wave. If the onset of the $P$ wave was difficult to define, the activation time was measured from the onset of the local electrogram to coronary sinus ostium. The radiofrequency energy delivered was 20-50 $\mathrm{W}$, and the temperature limit was individually set to $50-70 \mathrm{oC}$.

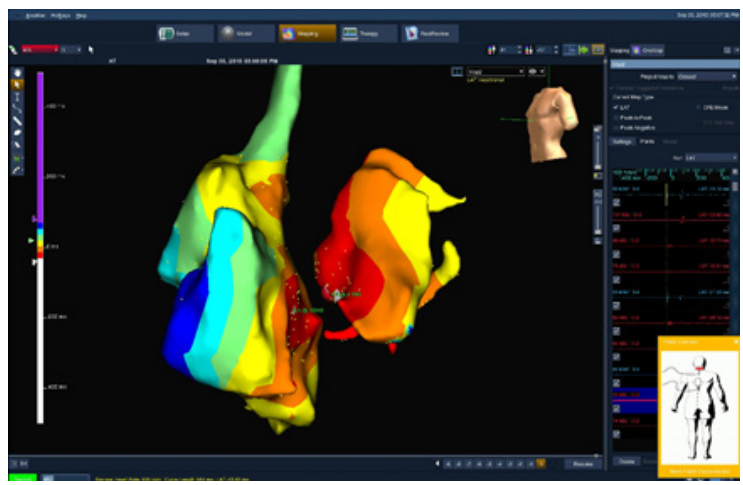

Figure 3: A 16-year-old female patient with AT in the left septal. The atrium was constructed geometry by Inquiry catheter. The electrogram located in the right septal at $35 \mathrm{~ms}$ before the coronary sinus ostium electrogram. However, the left septal electrogram was earlier at $45 \mathrm{~ms}$ before the coronary sinus ostium electrogram. The successful ablation site located in left septal. 
Follow up: The patients underwent follow-up by an electrophysiologist in the hospital outpatient clinic from postprocedure to at least 6 months after the procedure. If patients could not follow-up in the clinic, they were followed up by telephone interviews. Twelve-lead ECGs or Holter recordings were performed in patients with symptomatic palpitations.

Successful criteria: Acute success was defined as the noninducibility of the AT by programmed extra stimuli and/or isoproterenol administration. Long-term success was defined as a lack of electrocardiographically evident AT. Recurrence was defined as symptomatic and/or asymptomatic episodes of AT confirmed by ECG or Holter recordings. A second procedure was done if symptomatic recurrence was documented.

Statistical analysis: All data were summarized using frequencies and percentages for categorical data and mean \pm standard deviation (SD) for continuous data. Comparisons between groups were performed with Chi-square, Fisher's exact test and 2 sample t-test as appropriate. Statistical analysis was performed using IBM SPSS software for Windows version 20.0. (Armonk, NY: IBM Corp). A p-value of less than 0.05 was considered statistically significant.

\section{Results}

During the study period, 112 patients of AT underwent catheter ablation. The conventional catheter ablation was attempted in 73 patients, whereas 43 patients underwent the flouroless catheter ablation. The mean age was $50.46 \pm 17.77$ years (from 4 years old to 85 years old), with males accounting for $33.9 \%$. Table 1 shows patient baseline characters. Demographics in the group I were similar to those in the group II, except higher age of group I (53.11 \pm 16.73 years in group I versus $45.05 \pm 19.40$ years in group II; $p<0.05$ ) and a higher number of children in group II (1.3\% in group I versus $11.6 \%$ in group $\| ; p<0.05)$.

Table 1: Baseline characters of the studied population.

\begin{tabular}{|l|l|l|l|}
\hline & Group I (n=73) & Group II (n=43) & p \\
\hline $\begin{array}{l}\text { Age (years, } \\
\text { mean } \pm \text { SD) }\end{array}$ & $53.11 \pm 16.73$ & $45.05 \pm 19.40$ & $<0.05$ \\
\hline Male sex (n, \%) & $24(32.8 \%)$ & $15(34.8 \%)$ & NS \\
\hline $\begin{array}{l}\text { Pregnancy (n, } \\
\%)\end{array}$ & 0 & $2(4.6 \%)$ & NS \\
\hline $\begin{array}{l}\text { Children under } \\
16 \text { year old } \\
\text { (n, \%) }\end{array}$ & $1(1.3 \%)$ & $5(11.6 \%)$ & $<0.05$ \\
\hline $\begin{array}{l}\text { Hypertension } \\
\text { (n, \%) }\end{array}$ & $12(16.4 \%)$ & $7(16.2 \%)$ & NS \\
\hline Diabetes (n, \%) & $3(4.1 \%)$ & $2(4.6 \%)$ & NS \\
\hline
\end{tabular}

\begin{tabular}{|l|l|l|l|}
\hline $\begin{array}{l}\text { Left Ventricular } \\
\text { Diastolic } \\
\text { diameter (mm, } \\
\text { mean } \pm \text { SD) }\end{array}$ & $44.32 \pm 6.83$ & $43.64 \pm 8.52$ & NS \\
\hline $\begin{array}{l}\text { Left Ventricular } \\
\text { Ejection } \\
\text { Fraction (mm, } \\
\text { mean } \pm \text { SD) }\end{array}$ & $62.16 \pm 10.17$ & $64.63 \pm 10.75$ & NS \\
\hline $\begin{array}{l}\text { LVEF }<40 \% \\
(\mathrm{n}, \%)\end{array}$ & $2(2.7 \%)$ & $3(6.9 \%)$ & NS \\
\hline
\end{tabular}

The group I was successful in 63 of 73 patients (86.3\%). Four patients who were unsuccessful in conventional catheter ablation, the second procedure were performed by flouroless catheter ablation. The total acute successful rate in group II was not significantly different from the group I ( $88.3 \%$ versus $86.3 \%$, respectively; $\mathrm{P}=\mathrm{NS}$ ). However, the first procedure acute successful rate in group II was significantly higher than in group I $(94.8 \%$ versus $86.3 \%$, respectively; $\mathrm{P}<0.05)$. In 4 patients who were unsuccessful in conventional catheter ablation, one patient got successful with flouroless catheter ablation. The detail of the successful rate shows in Table 2.

\begin{tabular}{|l|l|l|l|}
\hline \multicolumn{5}{|c|}{ Table 2: Successful rate and recurrence rate. } \\
\hline & Group I & Group II & p \\
\hline $\begin{array}{l}\text { Total acute } \\
\text { successful rate } \\
\text { (n, \%) }\end{array}$ & $\begin{array}{l}63 \mathrm{pts} / 73 \mathrm{pts} \\
(86.3 \%)\end{array}$ & $\begin{array}{l}38 \mathrm{pts} / 43 \mathrm{pts} \\
(88.3 \%)\end{array}$ & NS \\
\hline $\begin{array}{l}\text { Long term } \\
\text { successful rate } \\
\text { (n, \%) }\end{array}$ & $\begin{array}{l}58 \mathrm{pts} / 73 \mathrm{pts} \\
(79.4 \%)\end{array}$ & $\begin{array}{l}36 \mathrm{pts} / 43 \mathrm{pts} \\
(83.70 \%)\end{array}$ & NS \\
\hline $\begin{array}{l}\text { The first } \\
\text { procedure acute } \\
\text { successful rate } \\
\text { (n, \%) }\end{array}$ & $\begin{array}{l}63 \mathrm{pts} / 73 \mathrm{pts} \\
(86.3 \%)\end{array}$ & $\begin{array}{l}37 \mathrm{pts} / 39 \mathrm{pts} \\
(94.8 \%)\end{array}$ & $<0.05$ \\
\hline $\begin{array}{l}\text { Long term the } \\
\text { first procedure } \\
\text { successful rate } \\
(\mathrm{n}, \%)\end{array}$ & $\begin{array}{l}58 \mathrm{pts} / 73 \mathrm{pts} \\
(79.4 \%)\end{array}$ & $\begin{array}{l}35 \mathrm{pts} / 39 \mathrm{pts} \\
(89.74)\end{array}$ & $<0.05$ \\
\hline $\begin{array}{l}\text { Recurrence rate } \\
\text { (n, \%) }\end{array}$ & $\begin{array}{l}5 \mathrm{pts} / 63 \mathrm{pts} \\
(7.90 \%)\end{array}$ & $\begin{array}{l}2 \mathrm{pts} / 38 \mathrm{pts} \\
(5.30 \%)\end{array}$ & NS \\
\hline
\end{tabular}

Table 3 shows the characters of tachycardia and the location of AT. In group I, we met one patient with 2 types of tachycardia (one is AT and one is atrioventricular nodal reentrant tachycardia - AVNRT). In group II, we met one patient with AT after catheter ablation of atrial fibrillation. In group II, there were 2 patients with two foci of AT. We found more than $50 \%$ of foci located in crista terminals and coronary sinus in both groups. There was no significant difference regarding the localization of foci between the two groups. 
Table 3: Characters of tachycardia and location of AT

\begin{tabular}{|c|c|c|c|}
\hline & Group I & Group II & $\mathbf{p}$ \\
\hline $\begin{array}{l}\text { Other arrhythmia beside AT } \\
\text { Post ablation of atrial fibrillation (n,\%) } \\
\text { AVNRT }(n, \%)\end{array}$ & $\begin{array}{l}0 \\
1(1.3 \%)\end{array}$ & $\begin{array}{l}1(2.3 \%) \\
0\end{array}$ & $\begin{array}{l}\text { NS } \\
\text { NS }\end{array}$ \\
\hline Two foci of AT $(n, \%)$ & 0 & $2(4.6 \%)$ & NS \\
\hline \multicolumn{4}{|l|}{ Location of AT } \\
\hline Crista terminalis $(n, \%)$ & $24(32.8 \%)$ & $16(35.5 \%)$ & NS \\
\hline Coronary sinus $(n, \%)$ & $18(24.6 \%)$ & $10(22.2 \%)$ & NS \\
\hline Perinodal tissue $(n, \%)$ & $11(15.0 \%)$ & $5(11.1 \%)$ & NS \\
\hline Right septal $(n, \%)$ & $3(4.1 \%)$ & $2(4.4 \%)$ & NS \\
\hline Tricuspid annulus $(n, \%)$ & $8(10.9 \%)$ & $3(6.6 \%)$ & NS \\
\hline Superior vena cava $(n, \%)$ & $3(4.1 \%)$ & $2(4.4 \%)$ & NS \\
\hline Right atrial appendage $(n, \%)$ & 0 & $1(2.2 \%)$ & NS \\
\hline Non-coronary cusp $(n, \%)$ & $1(1.3 \%)$ & 0 & NS \\
\hline Pulmonary vein $(n, \%)$ & 0 & $1(2.2 \%)$ & NS \\
\hline Left septal $(\mathrm{n}, \%)$ & 0 & $1(2.2 \%)$ & NS \\
\hline Mitral annulus $(n, \%)$ & $4(5.4 \%)$ & $3(6.6 \%)$ & NS \\
\hline Coronary sinus body $(n, \%)$ & $1(1.3 \%)$ & $1(2.2 \%)$ & NS \\
\hline
\end{tabular}

Data related to catheter ablation procedures is presented in Table 4. The fluoroscopy time, radiofrequency (RF) delivery time of group I was significantly longer than the group II, respectively (904.26 \pm 547.56 seconds in group I versus 169.21 \pm 85.66 seconds in group Il; $p<0.001)$; $(157.32 \pm 81.82$ seconds in group I versus $95.87 \pm 55.24$ seconds in group II; $p<0.001$ ). The number of RF applications of group I was significantly higher than the group II $(8.65 \pm 8.15$ times versus $6.05 \pm 4.69$ times respectively; $\mathrm{p}<0.01)$. However, there was no significant difference between 2 groups in procedure time $(68.71 \pm 28.76$ minutes in group I versus $66.34 \pm 26.48$ minutes in group II; $\mathrm{p}=\mathrm{NS}$ ).

Complication: No major complication was related to the procedures. Only one minor complication was hematomas in group II.

\section{Table 4: Data related to the catheter ablation procedure.}

\begin{tabular}{|l|l|l|l|}
\hline & Group I $(\mathbf{n}=\mathbf{7 3})$ & Group II $(\mathbf{n}=\mathbf{4 3})$ & $\mathbf{p}$ \\
\hline $\begin{array}{l}\text { Procedure time } \\
\text { (minutes) }\end{array}$ & $78.71 \pm 38.76$ & $76.34 \pm 36.48$ & NS \\
\hline $\begin{array}{l}\text { Fluoroscopy } \\
\text { time (seconds) }\end{array}$ & $904.26 \pm 547.56$ & $169.21 \pm 85.66$ & $<0.001$ \\
\hline $\begin{array}{l}\text { Number of RF } \\
\text { application }\end{array}$ & $8.65 \pm 8.15$ & $6.05 \pm 4.69$ & $<0.01$ \\
\hline $\begin{array}{l}\text { RF delivery time } \\
\text { (seconds) }\end{array}$ & $157.32 \pm 81.82$ & $95.87 \pm 55.24$ & $<0.001$ \\
\hline
\end{tabular}

Follow up: In group I, 56 patients were followed up in the clinic and 7 patients were followed up on the phone. In group II, 33 patients were followed up in the clinic and 5 patients were followed up on the phone. After 6 months follow-up, 5 of 63 patients $(7.9 \%)$ in group I and 2 of 38 patients (5.3\%) in group II had a recurrence of AT.

\section{Discussion:}

Based on data of prior publications, conventional mapping can still be a beneficial choice to guide catheter ablation based on the high success rate and lower cost [6]. Our data also shows that conventional catheter ablation does not differ much in the procedure time compared to fluoroless catheter ablation. The old data shows that the success rate of conventional catheter ablation was $75 \%$ to $92 \%$ [6-9]. The successful rate of flouroless catheter ablation was $90 \%$ to $98.5 \%$ in some special populations [10-12].

Our study shows that the success rate improved significantly when flouroless catheter ablation was used. Besides, conventional mapping has been well established that radiation exposure increases the lifetime risk of malignancies, genetic defects, skin injuries, and cataracts [13]. Studies have shown the radiation exposure received from 53 minutes to 60 minutes of fluoroscopy during ablation procedures might result in 0.7-1.4 fatal malignancies per 1,000 women and 1.0-2.6 per 1,000 men [14]. 3D mapping has reduced fluoroscopy times. The reduction of radiation with the use of 3D mapping systems, catheter ablation has brought new hope to special patients, such as pregnant women and children. In our study, there are 2 cases of pregnant patients that we find that it is difficult to perform in conventional catheter ablation due to the risk of radiation in pregnant women. In previous guidelines, the catheter ablation for pregnancy is not strongly recommended with class II b (level of evidence C) for supraventricular tachycardia [15]. However, the new ESC Guideline for supraventricular tachycardia is a more recommended flourless catheter ablation in pregnant cases of drug-refractory or poorly tolerated supraventricular tachycardia at the experienced centers with class II a [16]. The other group of patients who benefit most from flouroless catheter ablation procedures is children. The radiation dose reduction of pediatric patients might be as much as 10 times more radiosensitive than adults [17]. A larger number of centers have reported the use of 3D mapping tools for catheter ablation in children seems to allow a reproducible approach that does not increase the risk of complications [18-20]. In our study, the young patients were recommended 
to do flouroless catheter ablation that is why the age in the group of flouroless catheter ablation was lower than the age in the group of conventional catheter ablation. Recently, APHRS expert consensus on 3D mapping was strongly recommended with class I (level of evidence $\mathrm{C}$ ) for flouroless catheter ablation in children [21].

Our study also shows that the flouroless catheter ablation can reduce the number of RF application and RF delivery time; this can reduce heart damage more and avoid complications compared to conventional catheter ablation. However, this difference needs a larger number of patients to be confirmed. From our data, we recommend using the flouroless catheter ablation for patients with atrial tachycardia.

\section{Conclusion}

The fluoroless catheter ablation enhanced a more successful rate than the conventional catheter ablation. The fluoroless catheter ablation can reduce fluoroscopy time, radiofrequency delivery time and a number of radiofrequency applications compared to conventional catheter ablation. However, there was no difference between 2 methods in procedure time.

\section{Limitation of the study}

Our study has some limitations. This was a retrospective and observational study in a single center (4 operators with different experience: from 3 years to more 20 years in electrophysiology). Due to the nonrandomized nature, this study does not ensure homogeneity between the 2 groups. The follow-up has been based on symptomatic recurrence, ECG and Holter monitoring. In addition, some patients were followed up by telephone interviews.

\section{Conflicts of Interest}

The authors declare that this study was conducted in the absence of any commercial or financial relationships that are construed as a potential conflict of interest.

\section{References}

1. Klersy C, Chimienti M, Marangoni E, et al. Factors that predict spontaneous remission of ectopic atrial tachycardia. Eur Heart J. 14(12): 1654-1656 (1993).

2. Ellenbogen KA, Stambler BS. Atrial Tachycardia. In: Douglas Zipes \& Jose Jalife Cardiac Electrophysiology: from Cell to Bedside. 6th edition, Philadelphia, Saunders. p. 699-722 (2014)

3. Pap R, Kohári M, Makai $A$, et al. Surgical technique and the mechanism of atrial tachycardia late after open heart surgery. J Interv Card Electrophysiol. 35:127-135 (2012).

4. Patel AM, d'Avila A, Neuzil P et al. Atrial tachycardia after ablation of persistent atrial fibrillation. Circulation: Arrhythmia and Electrophysiology.1(1): 14-22 (2008).

5. Issa ZF, Miller JM, Zipes DP. Focal atrial tachycardia. In: Clinical Arrhythmology and Electrophysiology. A companion to Braunwald's Heart Disease, 2nd edition, Philadelphia, Saunders. p. 212-237 (2012)

6. Szegedi N, Zima E, Clemens M, et al. Radiofrequency ablation of focal atrial tachycardia: Benefit of electroanatomical mapping over conventional mapping. Acta Physiologica Hungarica. 102(3): 252-262 (2015).

7. Anguera I, Brugada J, Roba M, et al. Outcomes after catheter ablation of atrial tachycardia. Am Heart J. 87(7): 886-890 (2001).

8. Poty H, Saoudi N, Haissaguerre M, et al. Radiofrequency catheter ablation of atrial tachycardia. Am Heart J. 131(3): 481-489 (1996).

9. Manolis AS, Lazaridis K. Focal atrial tachycardia ablation: Highly successful with conventional mapping. J Intervent Card Electrophysiol. 55: 35-46 (2019).

10. Medi C, Kalman JM, Haqqani $H$, et al. Tachycardia mediated cardiomyopathy secondary to focal atrial tachycardia: long-term outcome after catheter ablation. J Am Coll Cardiol. 53(9): 1791-1797 (2009).

11. Morris GM, Segan L, Wong G, et al. Atrial tachycardia arising from the crista terminalis, detailed electrophysiological features and long term ablation outcome. J Am Coll Cardiol EP: 5(4): 448-458 (2019).

12. Grubb CS, Lewis $M$, Whang W, et al. Catheter ablation for atrial tachycardia in adults with congenital heart disease. J Am Coll Cardiol EP. 5(4): 438-447 (2019)

13. McFadden SL, Mooney RB, Shepherd PH. X-ray dose and associated risks from radiofrequency catheter ablation procedures. Br J Radiol. 75(891): 253-265 (2002).

14. Lickfett L, Mahesh M, Vasamareddy C, et al. Radiation exposure during catheter ablation of atrial fibrillation. Circulation. 110(19): 3003-3010 (2004).

15. Page R, Joglar JA, Caldwell MA, et al. 2015 ACC/AHA/HRS guideline for management of adult patients with supraventricular tachycardia. Heart Rhythm. 67(13): e136-e221 (2016).

16. Brugada J, Katritsis DG, Arbelo E, et al. 2019 ESC Guidelines for the management of patients with supraventricular tachycardia. Eur Heart J. 1: 1-66 (2019).

17. Strauss KJ, Kaste SC. The ALARA concept in pediatric interventional and fluoroscopic imaging: striving to keep radiation doses as low as possible during fluoroscopy of peadiatric patients- A white paper excutive summary. J Am Coll Radiol. 3(9): 686-688 (2006)

18. Mad DY, Miyake CY, Sherwin ED, et al. The use of an integrated electroanatomic mapping system and intracardiac echocardiography to reduce radiation exposure in children and young adults undergoing ablation of supraventricular tachycardia. Europace 16(2): 277-283 (2014).

19. Dieks JK, Muller MJ, Schneider HE, et al. Catheter ablation of pediatric focal atrial tachycardia: Ten year experience using modern mapping systems. Pediatr Cardiol. 37(3): 459-464 (2016).

20. Kang KT, Etheridge SP, Kantoch MJ, Dupanovic TS et al. Current management of focal tachycardia in children: a multicenter experience. Circ Arrhythm Electrophysiol. 7(4): 664-670 (2014). 


\section{Research Article}

21. Kim YH, Chen SA, Ernst S, Guzman CE et al. 2019 APHRS expert consensus statement on three dimensional mapping systems for tachycardia developed in collaboration with HRS, EHRA, and LAHRS. Journal of Arrhythmia. 1(1):1-56 (2020). 